\title{
Mitochondrial targeting of JNK/SAPK in the phorbol ester response of myeloid leukemia cells
}

\author{
Y Ito ${ }^{1}$, NC Mishra ${ }^{2}, K_{\text {Yoshida }}{ }^{1}$, S Kharbanda ${ }^{1}$, S Saxena ${ }^{2}$ and \\ D Kufe ${ }^{*, 1}$ \\ ${ }^{1}$ Dana-Farber Cancer Institute, Harvard Medical School, Boston, MA 02115, \\ USA \\ ${ }^{2}$ Lovelace Respiratory Research Institute, Albuquerque, NM 87115, USA \\ * Corresponding author: D Kufe, Dana-Farber Cancer Institute, Boston MA \\ 02115, USA. Tel: (617) 632-3141; Fax: (617) 632-2934; \\ E-mail: Donald-Kufe@dfci.harward.edu
}

Received 14.12.00; revised 7.3.01; accepted 13.3.01

Edited by $\mathrm{G}$ Salvesen

\begin{abstract}
Treatment of human U-937 myeloid leukemia cells with 12-0tetradecanoylphorbol-13-acetate (TPA) is associated with activation of the stress-activated protein kinase (SAPK) and induction of terminal monocytic differentiation. The present studies demonstrate that TPA targets SAPK to mitochondria by a mechanism dependent on activation of protein kinase $C$ (PKC) $\beta$. Translocation of SAPK to mitochondria in response to TPA is associated with release of cytochrome $c$, caspase-3 activation and induction of apoptosis. The results show that TPA induces the association of SAPK with the mitochondrial anti-apoptotic $\mathrm{Bcl}-\mathrm{x}_{\mathrm{L}}$ protein. Overexpression of $\mathrm{Bcl}-\mathrm{x}_{\mathrm{L}}$ attenuated the apoptotic response to TPA treatment. Moreover, expression of $\mathrm{Bcl}-\mathrm{x}_{\mathrm{L}}$ mutated at sites of SAPK phosphorylation (Thr-47, -115) was more effective than wildtype $\mathrm{Bcl}-\mathrm{x}_{\mathrm{L}}$ in abrogating TPA-induced cytochrome $c$ release and apoptosis. By contrast, expression of Bcl- $x_{L}$ had little effect on induction of the monocytic phenotype. These findings indicate that myeloid leukemia cells respond to TPA with targeting of SAPK to mitochondria and that this response contributes to terminal differentiation through the release of cytochrome $c$ and induction of apoptosis. Cell Death and Differentiation (2001) 8, 794-800.
\end{abstract}

Keywords: terminal differentiation; TPA; protein kinase $\mathrm{C} \beta$; stressactivated protein kinase; mitochondria; $\mathrm{Bcl}-\mathrm{x}_{\mathrm{L}}$

Abbreviations: TPA, 12-O-tetradecanoylphorbol-13-acetate; PKC, protein kinase C; SAPK/JNK, stress-activated protein kinase/c-Jun $\mathrm{NH}$-terminal kinase; PI, propidium iodide; DAPI, 4,6-diamino-2-phenylindole; HSP, heat shock protein; PCNA, proliferating cell nuclear antigen; PDGF, platelet-derived growth factor; ERK, extracellular signal regulated kinase; ER, endoplasmic reticulum

\section{Introduction}

Human U-937 and HL-60 myeloid leukemia cell lines proliferate autonomously in the absence of exogenous hematopoietic growth factors. ${ }^{1,2}$ These cells, however, respond to 12-O-tetradecanoylphorbol-13-acetate (TPA) and other agents that activate protein kinase $C$ (PKC) with induction of a differentiated monocytic phenotype and apoptosis. ${ }^{1-3}$ Resistance of human myeloid leukemia cells to TPA is associated with down-regulation or functional defects in $\mathrm{PKC} \beta$ expression. ${ }^{4-9}$ Moreover, induction of PKC $\beta$ expression by retinoic acid treatment or transfection of the PKC $\beta$ gene restores TPA-induced differentiation. ${ }^{7,10}$ These findings have indicated that factor-independent growth of myeloid leukemia cells is reversible by activation of $\operatorname{PKC} \beta$ mediated signals.

Other studies have shown that TPA treatment of myeloid leukemia cells is associated with induction of the stressactivated protein kinase (JNK/SAPK) and that this response is dependent on $\mathrm{PKC} \beta$ expression. ${ }^{11}$ SAPK is a serine/ threonine kinase that is related to the MAPK family and is induced by diverse types of stress. ${ }^{12,13}$ SAPK phosphorylates the $\mathrm{N}$-terminus of $\mathrm{C}$-Jun and thereby activates the cJun transcription function. ${ }^{12,13}$ The ATF2 and Elk1 transcription factors are also phosphorylated by SAPK. ${ }^{14-16}$ In concert with these results, TPA-induced activation of SAPK in myeloid leukemia cells is associated with induction of the c-jun gene. ${ }^{17-19}$ The early growth response 1 (EGR1) gene is also activated during TPA-induced monocytic differentiation and is necessary for appearance of the monocytic phenotype. ${ }^{20-22}$ These findings have supported a model in which TPA treatment of myeloid leukemia cells is associated with activation of $\operatorname{PKC} \beta$ and thereby the induction of SAPK activity and early response gene expression.

The present studies demonstrate that TPA-induced activation of $\mathrm{PKC} \beta$ targets SAPK to mitochondria. The results show that SAPK interacts with the anti-apoptotic $\mathrm{Bcl}-\mathrm{x}_{\mathrm{L}}$ protein and induces the release of cytochrome $c$. The findings support a role for mitochondrial targeting of SAPK in the apoptotic response of myeloid leukemia cells to TPA.

\section{Results and Discussion}

To assess the effects of TPA on the subcellular distribution of SAPK, intracellular fluorescence was measured with a high sensitivity CCD camera and image analyzer. Examination of the distribution of fluorescence markers in control U-937 cells showed distinct patterns for anti-SAPK (red signal) and the mitochondrion-selective dye Mitotracker (green signal) (Figure 1A). By contrast, treatment with TPA was associated with a change in fluorescence signals (red and green $\rightarrow$ yellow/ orange) that supported translocation of SAPK to mitochondria 
A.

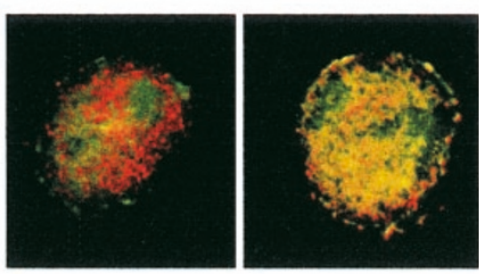

B.

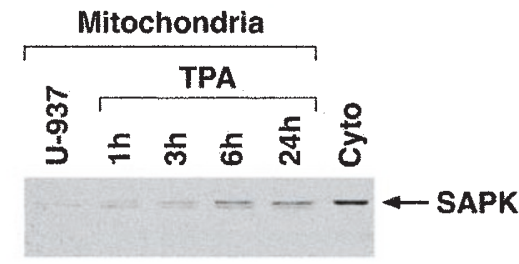

Fold: $1.01 .32 .5 \quad 5.55 .5$

IB: anti-SAPK

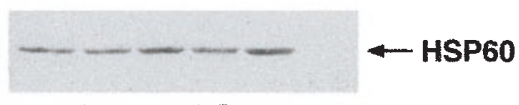

IB: anti-HSP60

$\leftarrow \beta$-actin

IB: anti- $\beta$-actin

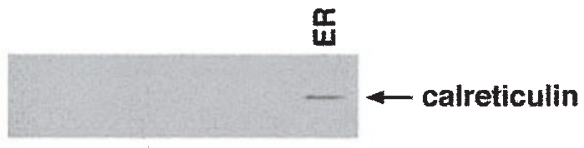

IB: anti-calreticulin

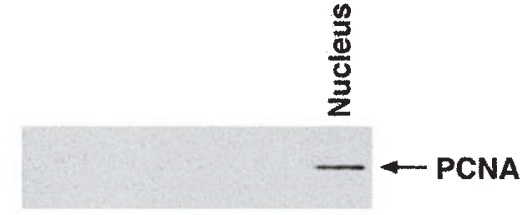

IB: anti-PCNA

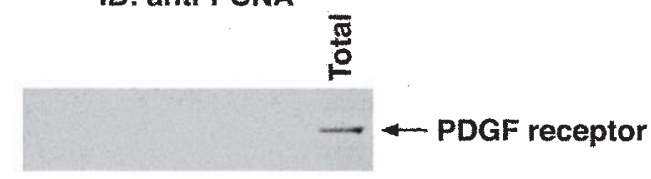

IB: anti-PDGF receptor

C.

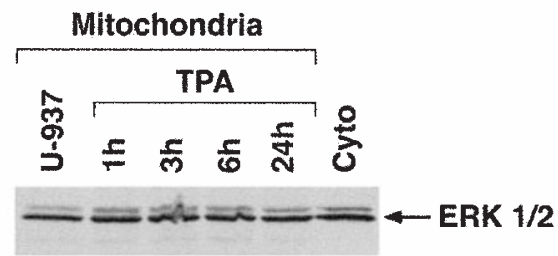

IB: anti-ERK $1 / 2$

Figure 1 Translocation of JNK/SAPK to mitochondria in response to TPA (A) U-937 cells were treated with $50 \mathrm{nM}$ TPA for $6 \mathrm{~h}$. After washing, the cells were immobilized on slides, fixed, and incubated with anti-SAPK antibody followed by Texas Red-conjugated goat anti-rabbit IgG. Mitochondria were stained with the mitochondrial-selective dye Mitotracker Green. Nuclei were stained with DAPI. The slides were visualized using a fluorescence microscope coupled to a high sensitivity CCD camera and image analyzer. Red signal, JNK/SAPK; green signal, Mitotracker; yellow/orange signals, colocalization of SAPK and Mitotracker. (B) U-937 cells were treated with TPA and harvested at the indicated times. Mitochondrial fractions were isolated and subjected to immunoblotting with anti-SAPK, anti-HSP60, anti- $\beta$-actin, anticalreticulin, anti-PDGF receptor or anti-PCNA. Cytoplasmic (Cyto), endoplas-
(Figure 1A). To confirm these finding, mitochondrial lysates were subjected to immunoblotting with anti-SAPK. The results demonstrate that TPA induces over a fivefold increase in mitochondrial levels of SAPK (Figure 1B). Equal loading of the lanes was confirmed by immunoblot analysis of the mitochondrial HSP60 protein (Figure 1B). Purity of the mitochondrial fraction was assessed by immunoblotting with antibodies against the cytoplasmic $\beta$-actin protein, the ERassociated calreticulin, the nuclear PCNA protein and the cell membrane PDGF receptor (Figure 1B). Moreover, the selectivity of TPA-induced translocation of SAPK was supported by the absence of detectable changes in mitochondrial levels of ERK 1/2 (Figure 1C). These findings demonstrate that TPA induces SAPK to translocate to mitochondria.

Previous work has demonstrated that the TPA-resistant U-937 clone, designated TUR, is defective in TPA-induced activation of SAPK. ${ }^{11}$ To determine whether induction of SAPK activity is necessary for translocation to mitochondria, TUR cells were treated with TPA and mitochondrial lysates were analyzed by immunoblotting with anti-SAPK. The results demonstrate little effect of TPA on mitochondrial levels of SAPK (Figure 2A). Mitochondrial lysates from TPA-treated U-937 and TUR cells were also subjected to immunoprecipitation with anti-SAPK. Analysis of the precipitates for phosphorylation of GST-Jun demonstrated induction of SAPK activity in TPA-treated U-937, but not TUR, cells (Figure 2B). To assess whether $\mathrm{PKC} \beta$ is required for TPA-induced translocation of SAPK to mitochondria, TUR cells were studied that stably express the $\mathrm{PKC} \beta$ gene. ${ }^{11}$ The results show that TPA treatment of TUR/PKC $\beta$ cells is associated with translocation of SAPK to mitochondria (Figure 2C). To provide further support for PKC $\beta$-mediated translocation of SAPK to mitochondria, $U$ 937 cells were pretreated with the PKC inhibitor, calphostin C. The results demonstrate that calphostin $C$ blocks TPAinduced targeting of SAPK to mitochondria (Figure 2D). Other studies have demonstrated that okadaic acid induces U-937 cell differentiation by a PKC $\beta$-independent mechanism. ${ }^{9}$ In contrast to TPA, okadaic acid had little if any effect on mitochondrial SAPK levels (Figure $2 \mathrm{E}$ ). These findings support a model in which TPA-induced activation of the $\operatorname{PKC} \beta \rightarrow$ SAPK pathway is necessary for translocation of SAPK to mitochondria.

U-937 cells respond to TPA with the induction of differentiation and apoptosis. ${ }^{3}$ To determine whether targeting SAPK to mitochondria is associated with apoptosis, U-937, TUR and TUR/PKC $\beta$ cells were studied for TPA-induced release of mitochondrial cytochrome $c$ and activation of caspase-3. The results demonstrate that $U$ 937, but not TUR, cells respond to TPA with release of cytochrome $c$ to the cytosol (Figure 3A). Moreover, the TUR/PKC $\beta$ cells responded to TPA with cytochrome $c$

mic reticulum (ER), nuclear fractions and total cell lysates (total) were used as controls. Signal intensities were analyzed by densitometric scanning. The intensity of the SAPK signals was compared to that of the untreated control. (C U-937 cells were treated with TPA for the indicated times. Mitochondrial fractions were subjected to immunoblotting with anti-ERK $1 / 2$ 
A.

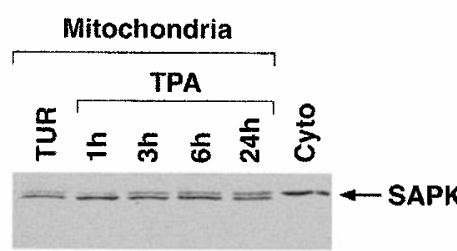

Fold: $1.0 \quad 0.91 .41 .51 .5$

IB: anti-SAPK

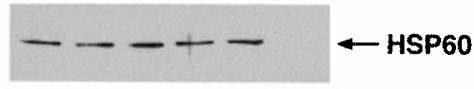

IB: anti-HSP60

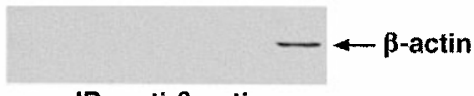

IB: anti- $\beta$-actin

B.

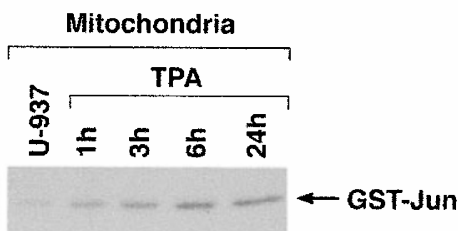

Fold: $\begin{array}{lllll}1.0 & 2.7 & 3.8 & 5.4 & 6.1\end{array}$

IP: anti-SAPK
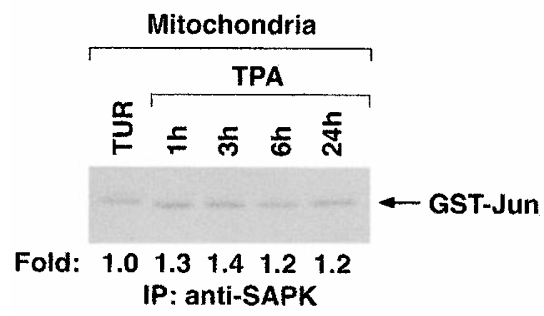

C.

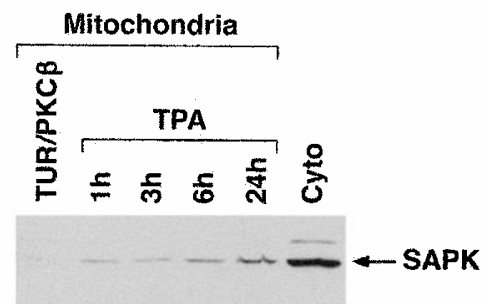

Fold: $1.0 \quad 2.93 .0 \quad 5.46 .8$

IB: anti-SAPK

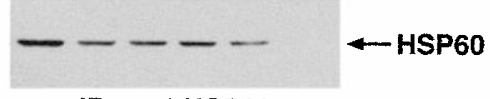

IB: anti-HSP60

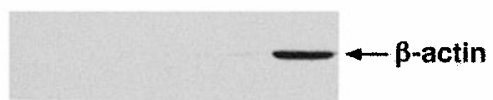

IB: anti- $\beta$-actin

D. Mitochondria

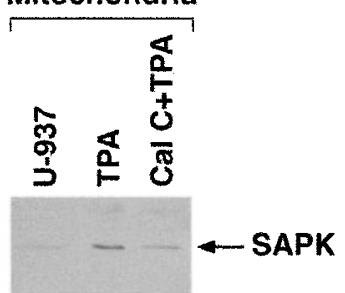

Fold: $1.0 \quad 5.31 .8$

IB: anti-SAPK

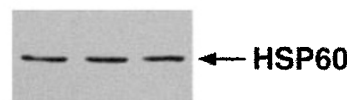

IB: anti-HSP60

E.

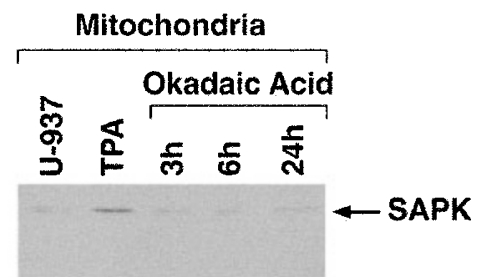

Fold: $1.05 .2 \quad 1.1 \quad 1.1 \quad 1.5$

IB: anti-SAPK

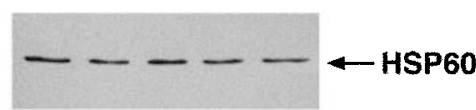

IB: anti-HSP60

Figure 2 PKC $\beta$ expression is required for TPA-induced translocation of JNK/SAPK to mitochondria. (A) TUR cells were treated with TPA and harvested at the indicated times. Mitochondrial fractions were subjected to immunoblotting with anti-SAPK (upper panel), anti-HSP60 (middle panel) or anti- $\beta$-actin (lower panel). Cytoplasmic (Cyto) fraction was used as a control. Intensity of the SAPK signals was compared to that of the control. (B) U-937 (upper panel) and TUR (lower panel) cells were treated with TPA for the indicated times. Mitochondrial fractions were subjected to immunoprecipitation with anti-SAPK. The precipitates were analyzed in an immune complex kinase assay using GST-Jun as substrate. (C) TUR/PKC $\beta$ cells were treated with TPA for the indicated times. Mitochondrial fractions were subjected to immunoblotting with anti-SAPK (upper panel), anti-HSP60 (middle panel) or anti- $\beta$-actin (lower panel). Cytoplasmic (Cyto) fraction was used as a control. (D) U-937 cells were pretreated with $100 \mathrm{nM}$ calphostin $\mathrm{C}(\mathrm{Cal} \mathrm{C})$ for $1 \mathrm{~h}$ and then incubated with TPA for $6 \mathrm{~h}$. Mitochondrial fractions were subjected to immunoblotting with anti-SAPK (upper panel) and anti-HSP60 (lower panel). (E) U-937 cells were treated with TPA for $6 \mathrm{~h}$ or with $50 \mathrm{nM}$ okadaic acid for the indicated times. Mitochondrial fractions were subjected to immunoblotting with anti-SAPK (upper panel) and anti-HSP60 (lower panel). Intensity of the SAPK signals was compared to that of the untreated control 


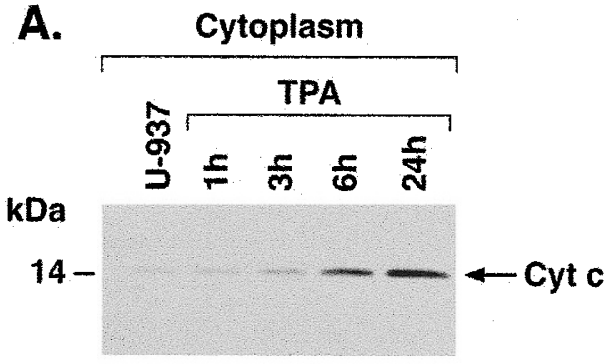

Fold: $\quad 1.01 .2 \quad 1.5 \quad 4.5 \quad 6.9$

IB: anti-Cyt c

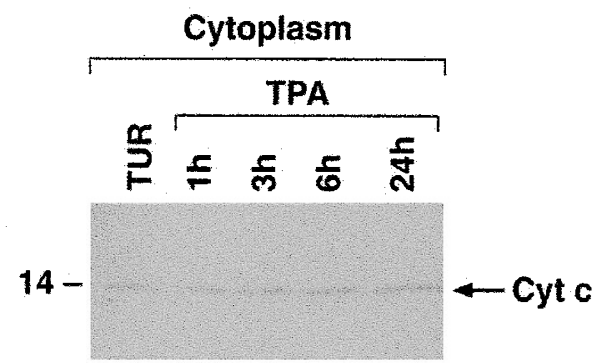

Fold: $1.0 \quad 1.0 \quad 1.1 \quad 1.2 \quad 1.8$

IB: anti-Cyt c

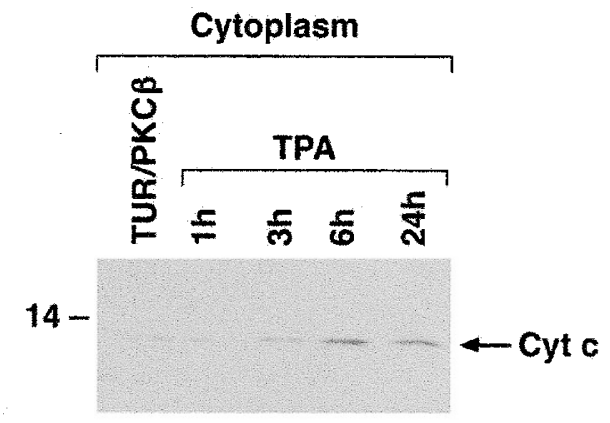

Fold: $1.0 \quad 2.12 .26 .6 \quad 6.1$

IB: anti-Cyt c
B.

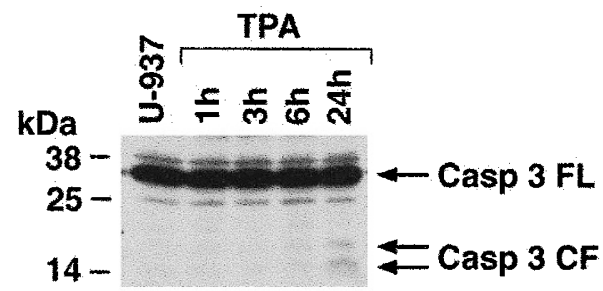

IB: anti-Caspase-3

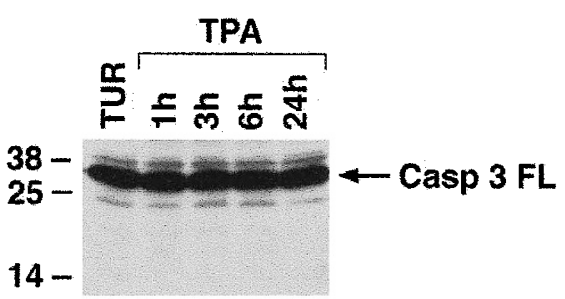

IB: anti-Caspase-3

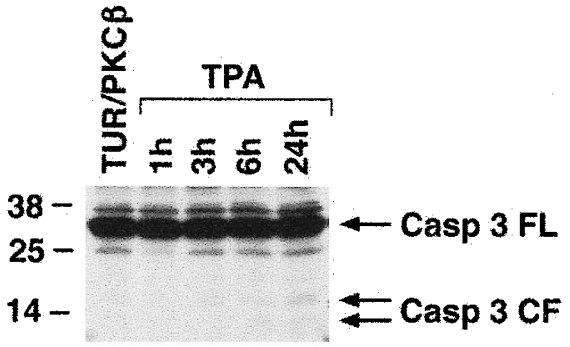

IB: anti-Caspase-3

Figure 3 TPA induces cytochrome $c$ release and caspase-3 activation and apoptosis by a PKC $\beta$-dependent mechanism. (A) U-937 (upper panel), TUR (middle panel) and TUR/PKC $\beta$ (lower panel) cells were treated with TPA and harvested at the indicated times. Cytoplasmic fractions were subjected to immunoblotting with anti-cytochrome $c($ Cyt $c)$. Intensity of the cytochrome $c$ signals was compared to that of the control. (B) Total cell lysates were analyzed by immunoblotting with anti-caspase-3 (Casp 3). FL, full length; CF, cleaved fragment

release (Figure 3A). Cytosolic cytochrome $c$ binds to Apaf1 , induces the autoprocessing of caspase- 9 and thereby the activation of caspase-3. ${ }^{23,24}$ In concert with TPAinduced release of cytochrome $c, \mathrm{U}-937$ and TUR/PKC $\beta$, but not TUR, cells responded to TPA with activation of caspase-3 (Figure 3B). These findings indicated that TPAinduced activation of the $\operatorname{PKC} \beta \rightarrow$ SAPK pathway is associated with the induction of cytochrome $c$ release and caspase-3 activation.

Previous work has shown that SAPK phosphorylates the mitochondrial $\mathrm{Bcl}-\mathrm{x}_{\llcorner}$protein on Thr-47 and Thr-115. ${ }^{25}$ To determine whether $\mathrm{Bcl}-\mathrm{x}_{\mathrm{L}}$ regulates TPA-induced signaling, studies were performed on U-937 cells stably overexpres- sing $\mathrm{BCl}-\mathrm{x}_{\mathrm{L}}\left(\mathrm{U}-937 / \mathrm{Bcl}-\mathrm{x}_{\mathrm{L}}\right){ }^{26} \mathrm{Bcl}-\mathrm{x}_{\mathrm{L}}$ expression had no detectable effect on TPA-induced translocation of SAPK to mitochondria (Figure 4A, left panel). Moreover, TPAtreatment induced the association of SAPK and $B c l-x_{L}$ (Figure 4A, right panel). By contrast, TPA-induced release of cytochrome $c$ was attenuated in the $U-937 / \mathrm{Bcl}-x_{L}$ cells (Figure $4 \mathrm{~A}$ ). Bcl- $\mathrm{x}_{\mathrm{L}}$ also had no effect on TPA-induced cell adhesion, a characteristic of monocytic differentiation ${ }^{11}$ (Figure 4B). To extend the analysis, other studies were performed on U-937 cells stably overexpressing $\mathrm{Bcl}-\mathrm{x}_{\mathrm{L}}$ in which Thr-47 and Thr-115 were mutated to alanines ( $U$ 937/Bcl- $\left.x_{\mathrm{L}}(\mathrm{A}-47,-115)\right) .{ }^{25}$ Overexpression of $\mathrm{Bcl}-\mathrm{x}_{\mathrm{L}}(\mathrm{A}-47$, -115) had no effect on TPA-induced translocation of SAPK, 
but blocked cytochrome $c$ release compared to that obtained with $U-937$ and $U-937 / B c l-x_{L}$ cells (Figure $4 \mathrm{C}$ ). $\mathrm{Bcl}-\mathrm{x}_{\mathrm{L}}(\mathrm{A}-47,-115)$ also had no effect on TPA-induced cell
A.
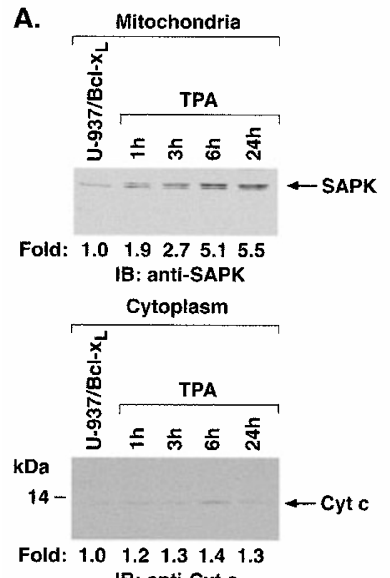

IB: anti-Cyt c

B.

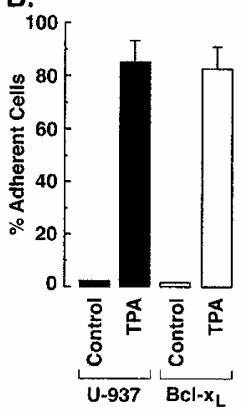

D.

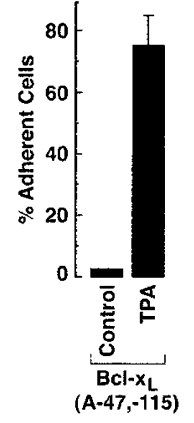

$\mathrm{kDa}$

$50-$
$37-$
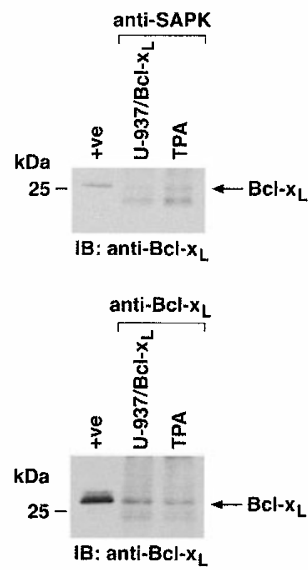

C. Mitochondria

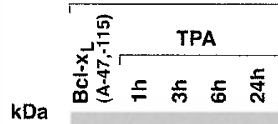

Fold: $\quad \begin{array}{lllll}1.0 & 2.2 & 2.0 & 4.8 & 4.6\end{array}$

IB: anti-SAPK

Cytoplasm

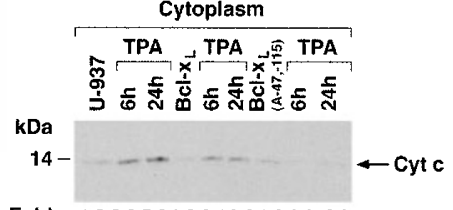

Fold: $\quad 1.03 .95 .01 .02 .12 .01 .00 .80 .9$ IB: anti-Cyt c

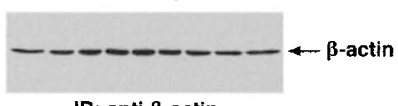

IB: anti- $\beta$-actin
Figure 4 Functional interaction between SAPK and $\mathrm{Bcl}-\mathrm{x}_{\mathrm{L}}$ in mitochondria. (A) U-937/Bcl- $X_{L}$ cells were treated with TPA and harvested at the indicated times. Mitochondrial and cytoplasmic fractions were subjected to immunoblotting with anti-SAPK (left upper panel) or anti-cytochrome $c$ (left lower panel). $\mathrm{U}-937 / \mathrm{Bcl}-\mathrm{x}_{\mathrm{L}}$ cells were treated with TPA for $6 \mathrm{~h}$. Mitochondrial fractions were subjected to immunoprecipitation with anti-SAPK or anti-Bcl- $x_{L}$. The immunoprecipitates were analyzed by immunoblotting with anti-Bcl- $\mathrm{x}_{\mathrm{L}}$ (right panels). (B) U-937 or U-937/Bcl- $x_{L}$ cells were treated with TPA for $24 \mathrm{~h}$. The percentage of adherent cells are expressed as the mean \pm S.D. from three independent experiments performed in duplicate for the U-937 (solid bar) and Bcl- $x_{\mathrm{L}}$ (open bar) cells. (C) U-937, U-937/Bcl- $x_{\mathrm{L}}$ and U-937/Bcl- $\mathrm{x}_{\mathrm{L}}(\mathrm{A}-47,-115)$ cells were treated with TPA and harvested at the indicated times. Mitochondrial and cytoplasmic fractions were subjected to immunoblotting with anti-SAPK (upper panel), anti-cytochrome $c$ (middle panel) or anti- $\beta$-actin (lower panel). (D) U-937/Bcl- $x_{\mathrm{L}}(\mathrm{A}-47,-115)$ cells were treated with TPA for $24 \mathrm{~h}$. The percentage of adherent cells is expressed as the mean \pm S.D. from three independent experiments each performed in duplicate. Intensity of the SAPK and cytochrome $c$ signals was compared to that of the untreated control adhesion (Figure 4D). These results support a role for targeting of SAPK to mitochondria in the regulation of $\mathrm{Bcl}$ $\mathrm{X}_{\mathrm{L}}$ function and the release of cytochrome $c$.

In concert with the demonstration that TPA targets SAPK to mitochondria and thereby release of cytochrome $c, \mathrm{U}$ 937, and not TUR, cells responded to TPA with induction of apoptosis (Figure 5). Dependence of the apoptotic response on $\operatorname{PKC} \beta$ was supported by the finding that TUR/PKC $\beta$ cells also responded to TPA with induction of apoptosis (Figure 5). TPA-induced apoptosis was slower and less pronounced than that achieved when U-937 cells were treated with ionizing radiation (i.e., $40 \%$ apoptosis at $24 \mathrm{~h}) .{ }^{25}$ Indeed, other studies have demonstrated that ionizing radiation and TPA activate SAPK by distinct mechanisms. ${ }^{11,27}$ The present results also demonstrate that expression of $\mathrm{Bcl}-\mathrm{x}_{\mathrm{L}}$ blocks TPA-induced apoptosis (Figure 5). Moreover, the $\mathrm{Bcl}-\mathrm{x}_{\mathrm{L}}(\mathrm{A}-47,-115)$ mutant was more effective in blocking the apoptotic response to TPA treatment (Figure 5). These results provide further support for targeting of SAPK to mitochondria as a pro-apoptotic signal.

SAPK is activated in the TPA response of myeloid leukemia cells and is required for the induction of terminal monocytic differentiation. ${ }^{11}$ The present studies demonstrate that TPA targets SAPK to the mitochondria by a $\operatorname{PKC} \beta$-dependent mechanism. The results support a role for mitochondrial targeting of SAPK in a signaling cascade that

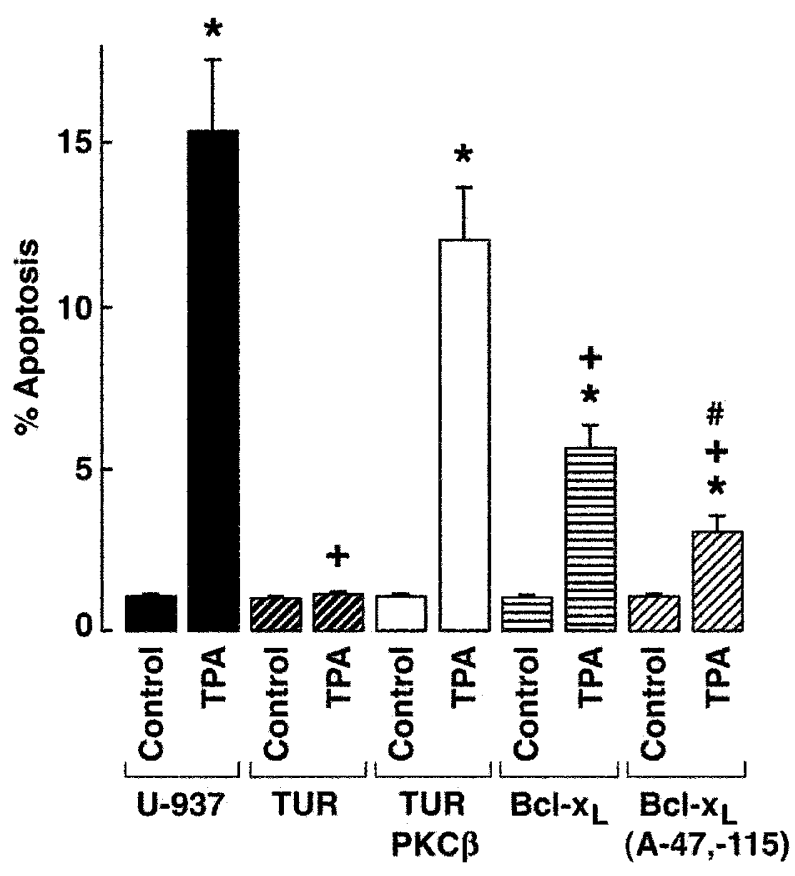

Figure 5 TPA-induced apoptosis is $\mathrm{PKC} \beta$-dependent and blocked by $\mathrm{Bcl}-\mathrm{x}_{\mathrm{L}}$. U-937, TUR, TUR/PKC $\beta, U-937 / \mathrm{Bcl}-\mathrm{x}_{\mathrm{L}}$ and $\mathrm{U}-937 / \mathrm{Bcl}-\mathrm{x}_{\mathrm{L}}(\mathrm{A}-47,-115)$ cells were treated with TPA for $24 \mathrm{~h}$. After fixing, cells were stained with propidium iodide and sub- $G_{1}$ DNA content was assayed by FACScan. The percentage of apoptotic cells with sub- $G_{1}$ DNA content is expressed as the mean \pm S.D. from three independent experiments each performed in duplicate. As determined by $t$-test, the significance of the following comparisons is: ${ }^{*} P<0.05$, versus control; $+P<0.05$, versus U-937/TPA; \#P<0.05, U-937/Bcl- $\mathrm{x}_{\mathrm{L}} / \mathrm{TPA}$ versus $\mathrm{U}$ 937/Bcl- $x_{L}(A-47,-115) / T P A$ 
confers TPA-induced apoptosis. In this context, SAPK interacts with the mitochondrial $\mathrm{Bcl}-\mathrm{x}_{\mathrm{L}}$ protein and overexpression of $\mathrm{Bcl}-\mathrm{x}_{\mathrm{L}}$ attenuates TPA-induced cytochrome $c$ release. Moreover, expression of $\mathrm{Bcl}-\mathrm{x}_{\mathrm{L}}$ mutated at sites of SAPK phosphorylation (Thr-47, -115) was more effective than wild-type $\mathrm{Bcl}-\mathrm{x}_{\mathrm{L}}$ in abrogating TPA-induced cytochrome $c$ release and apoptosis. $\mathrm{Bcl}-\mathrm{x}_{\mathrm{L}}$ regulates cytochrome $c$ release by the mitochondrial voltage dependent anion channel. ${ }^{28,29}$ Thr-47 resides in a 60-residue loop that is non-essential for the anti-apoptotic activity of $\mathrm{Bcl}-\mathrm{x}_{\mathrm{L}}$, while Thr-115 is adjacent to the $\alpha 3$ helix which may be structurally important in the formation of ion channels. ${ }^{30,31}$ Importantly, overexpression of Bcl- $x_{\mathrm{L}}$ had little if any effect on monocytic differentiation. These findings support a model in which TPA-induced activation of the PKC $\beta \rightarrow$ SAPK pathway contributes to terminal monocytic differentiation by targeting SAPK to $\mathrm{Bcl}-\mathrm{x}_{\mathrm{L}}$ in mitochondria and inducing cytochrome $c$ release, caspase-3 activation and apoptosis.

\section{Materials and Methods}

\section{Cell culture and reagents}

Human U-937 and TUR, ${ }^{9}$ TUR/PKC $\beta,{ }^{11} \mathrm{U}-937 / \mathrm{Bcl}-\mathrm{x}_{\mathrm{L}}{ }^{26}$ and U-937/ $\mathrm{Bcl}-\mathrm{x}_{\mathrm{L}}(\mathrm{A}-47,-115)$ cells were myeloid leukemia cells were grown in RPMI 1640 medium supplemented with $10 \%$ heat-inactivated fetal bovine serum, 100 units $/ \mathrm{ml}$ penicillin, $100 \mu \mathrm{g} / \mathrm{ml}$ streptomycin and $2 \mathrm{mM}$ L-glutamine. Cells were treated with $50 \mathrm{nM}$ TPA (Sigma Chemical Co.).

\section{Immunofluorescence microscopy}

Cells were fixed onto poly D-lysine coated glass coverslips with $3.7 \%$ formaldehyde/PBS ( $\mathrm{pH} \mathrm{7.4)}$ for $10 \mathrm{~min}$, washed with PBS, permeabilized with $0.2 \%$ Triton $\mathrm{X}-100$ for $10 \mathrm{~min}$, washed again and incubated for $30 \mathrm{~min}$ in complete medium. The coverslips were then incubated with $5 \mu \mathrm{g} / \mathrm{ml}$ of anti-SAPK polyclonal antibody (Santa Cruz) for $1 \mathrm{~h}$ followed by Texas Red-goat anti-rabbit $\mathrm{IgH}(\mathrm{H}+\mathrm{L})$ conjugate (Molecular Probes, Eugene, OR, USA). Mitochondria were stained with $100 \mathrm{nM}$ Mitotracker Green FM (Molecular Probes, OR, USA). Nuclei were stained with 4,6-diamino-2-phenylindole (DAPI; $1 \mu \mathrm{g} / \mathrm{ml}$ in PBS). Coverslips were mounted onto slides with $0.1 \mathrm{M}$ Tris ( $\mathrm{pH} 7.0)$ in $50 \%$ glycerol. Cells were visualized by digital confocal immunofluorescence and images were captured with a cooled CCD camera mounted on a Zeiss Axioplan 2 microscope. Images were deconvolved using Slidebook software (Intelligent Imaging Innovations, Inc., Denver, CO, USA).

\section{Isolation of mitochondrial, cytoplasmic and ER fractions}

Cells were washed twice with PBS, and cell fractionation was performed as described. ${ }^{28,32,33}$

\section{Immunoprecipitation and immunoblot analysis}

Soluble proteins were subjected to immunoprecipitation with antiSAPK as described. ${ }^{25}$ Immunoblot analysis was performed with antiSAPK (Santa Cruz), anti-HSP60 (StessGen, Victoria, British
Columbia), anti- $\beta$-actin (Sigma), anti-calreticulin (StessGen), antiPDGF receptor (Oncogene), anti-PCNA (Calbiochem), anti-ERK 1/2 (Santa Cruz) and anti-cytochrome $c^{34}$

\section{Immune complex kinase assays}

Soluble proteins were incubated with anti-SAPK (Santa Cruz) for $1 \mathrm{~h}$ and precipitated with protein A-Sepharose for an additional $1 \mathrm{~h}$. The resulting immune complexes were analyzed for phosphorylation of GST-Jun $(2-100)$ as described. ${ }^{11}$

\section{Apoptosis assays}

Cells were washed with PBS, fixed with $80 \%$ ethanol and incubated with $2.5 \mu \mathrm{g} / \mathrm{ml}$ propidium iodide and $50 \mu \mathrm{g} / \mathrm{ml}$ RNAse. FACScan (Becton Dickinson) was used to assess cells with sub-G1 DNA content.

\section{Acknowledgements}

The authors appreciate the technical assistance of Kamal Chauhan. This investigation was supported by PHS Grant CA42802 awarded by the National Cancer Institute, DHHS and by the Office of Health and Biological Research, US Department of Energy cooperative agreement DE-FC04-96AL76406.

\section{References}

1. Sundstrom C and Nilsson K (1976) Establishment and characterization of a human histiocytic lymphoma cell line (U-937). Int. J. Cancer 17: 565-577

2. Collins SJ (1987) The HL-60 promyelocytic leukemia cell line: proliferation, differentiation, and cellular oncogene expression. Blood 70: 1233-1244

3. Gunji $\mathrm{H}$, Hass R and Kufe D (1992) Activation of internucleosomal DNA fragmentation during phorbol ester-induced monocytic differentiation and $G_{0} / G_{1}$ arrest. J. Clin. Invest. 89: 954-960

4. Macfarlane DE and Manzel L (1994) Activation of beta-isozyme of protein kinase $\mathrm{C}$ (PKC beta) is necessary and sufficient for phorbol ester-induced differentiation of $\mathrm{HL}-60$ promyelocytes. Studies with PKC beta-defective PET mutant. J. Biol. Chem. 269: 4327-4331

5. Nishikawa M, Komada F, Uemura Y, Hidaka H and Shirakawa S (1990) Decreased expression of type II protein kinase $\mathrm{C}$ in $\mathrm{HL}-60$ variant cells resistant to induction of cell differentiation by phorbol diester. Cancer Res. 50:621-626

6. Tonetti DA, Horio M, Collart FR and Huberman E (1992) Protein kinase C beta gene expression is associated with susceptibility of human promyelocytic leukemia cells to phorbol ester-induced differentiation. Cell Growth Differ. 3: $739-745$

7. Tonetti DA, Henning-Chubbg C, Yamanishi DT and Huberman E (1994) Protein kinase $\mathrm{C}-\beta$ is required for macrophage differentiation of human $\mathrm{HL}-60$ leukemia cells. J. Biol. Chem. 269: 23230-23235

8. Kiley SC, Adams PD and Parker PJ (1997) Cloning and characterization of phorbol ester differentiation-resistant U937 cell variants. Cell Growth Differ. 8: $221-230$

9. Hass R, Hirano M, Kharbanda S, Rubin E and Kufe D (1993) Resistance to phorbol ester-induced differentiation of a U-937 myeloid leukemia cell variant with a signaling defect upstream to Raf-1 kinase. Cell Growth Differ. 4:657-663

10. Yang K, Mizobuchi T, Kharbanda S, Datta R, Huberman E, Kufe D and Stone R (1994) All-trans retinoic acid reverses phorbol ester resistance in a human myeloid leukemia cell line. Blood 83: 490-496

11. Kaneki M, Kharbanda S, Pandey P, Yoshida K, Takekawa M, Liou JR, Stone R and Kufe $D$ (1999) Functional role for protein kinase $C \beta$ as a regulator of stressactivated protein kinase activation and monocytic differentiation of myeloid leukemia cells. Mol. Cell. Biol. 19: 461-470 
12. Derijard B, Hibi M, Wu IH, Barrett T, Su B, Deng T, Karin M and Davis RJ (1994) JNK1: A protein kinase stimulated by UV light and $\mathrm{Ha}$-Ras that binds and phosphorylates the c-Jun activation domain. Cell 76: 1025-1037

13. Kyriakis JM, Banerjee P, Nikolakaki E, Dai T, Rubie EA, Ahmad MF, Avruch J and Woodgett JR (1994) The stress-activated protein kinase subfamily of c-Jun kinases. Nature 369: $156-160$

14. Gupta S, Campbell D, Dérijard B and Davis RJ (1995) Transcription factor ATF2 regulation by the JNK signal transduction pathway. Science 267: 389-393

15. Raingeaud J, Whitmarsh AJ, Barrett T, Derijard B and Davis RJ (1996) MKK3and MKK6-regulated gene expression is mediated by the $\mathrm{p} 38$ mitogen-activated signal transduction pathway. Mol. Cell. Biol. 16: 1247-1255

16. Whitmarsh AJ, Shore P, Sharrocks AD and Davis RJ (1995) Integration of MAP kinase signal transduction pathways at the serum response element. Science 269: $403-407$

17. Sherman M, Stone R, Datta R, Bernstein S and Kufe D (1990) Transcriptional and post-transcriptional regulation of c-jun expression during monocytic differentiation of human myeloid leukemic cells. J. Biol. Chem. 265: 3320-3323

18. Szabo E, Preis LH and Birrer MJ (1994) Constitutive cJun expression induces partial macrophage differentiation in U-937 cells. Cell Growth Differ. 5: 439-446

19. William F, WagnerF, Karin Mand Kraft AS (1990) Multiple doses of diacylglycerol and calcium ionophore are necessary to activate AP-1 enhancer activity and induce markers of macrophage differentiation. J. Biol. Chem. 265: 1816618171

20. Nguyen $H Q$, Liebermann HB and Liebermann DA (1993) The zinc finger transcription factor EGF-1 is essential for and restricts differentiation along the macrophage lineage. Cell 72: 197-209

21. Kharbanda S, Rubin E, Datta R, Hass R, Sukhatme V and Kufe D (1993) Transcriptional regulation of the early growth response 1 gene in human myeloid leukemia cells by okadaic acid. Cell Growth Differ. 4: 17-23

22. Kharbanda SM, Nakamura T, Stone R, Hass R, Bernstein S, Datta R, Sukhatme $V$ and Kufe $D$ (1991) Expression of the early growth response 1 and 2 zinc finger genes during induction of monocytic differentiation. J. Clin. Invest. 88: 571-577

23. Li P, Nijhawan D, Budihardjo I, Srinivasula SM, Ahmad M, Alnemri ES and Wang X (1997) Cytochrome $c$ and dATP-dependent formation of Apaf-1/caspase- 9 complex initiates an apoptotic protease cascade. Cell 91: 479-489

24. Zou H, Li X, Liu X and Wang X (1999) An APAF-1 Cytochrome c multimeric complex is a functional apoptosome that activates procaspase-9. J. Biol. Chem. 274: $11549-11556$
25. Kharbanda S, Saxena S, Yoshida K, Pandey P, Kaneki M, Wang Q, Cheng K, Chen Y, Campbell A, Thangrila S, Yuan Z, Narula J, Weichselbaum R, Nalin C and Kufe D (2000) Translocation of SAPK/JNK to mitochondria and interaction with BCl- $\mathrm{X}_{\mathrm{L}}$ in response to DNA damage. J. Biol. Chem. 275: 322-327

26. Datta R, Manome Y, Taneja N, Boise LH, Weichselbaum RR, Thompson CB, Slapak CA and Kufe DW (1995) Overexpression of Bcl- $\mathrm{X}_{\mathrm{L}}$ by cytotoxic drug exposure confers resistance to ionizing radiation-induced internucleosomal DNA fragmentation. Cell Growth Differ. 6: 363-370

27. Kharbanda S, Pandey P, Yamauchi T, Kumar S, Kaneki M, Kumar V, Bharti A, Yuan Z, Ghanem L, Rana A, Weichselbaum R, Johnson G and Kufe D (2000) Activation of MEK kinase- 1 by the c-Abl protein tyrosine kinase in response to DNA-damage. Mol. Cell. Biol. 20: 4979-4989

28. Kharbanda S, Pandey P, Schofield L, Israels S, Roncinske R, Yoshida K, Bharti A, Yuan Z, Saxena S, Weichselbaum R, Nalin Cand Kufe D (1997) Role for Bcl-- $\mathrm{K}_{\mathrm{L}}$ as an inhibitor of cytosolic cytochrome $\mathrm{C}$ accumulation in apoptosis. Proc. Natl. Acad. Sci. USA 94: 6939-6942

29. Shimizu S, Narita M and Tsujimoto Y (1999) Bcl-2 family proteins regulate the release of apoptogenic cytochrome $\mathrm{c}$ by the mitochondrial channel VDAC. Nature 399: $483-487$

30. Muchmore SW, Sattler M, Liang H, Meadows RP, Harlan JE, Yoon HS, Nettesheim D, Chang BS, Thompson CB, Wong S-L, Ng S-C and Fesik SW (1996) X-ray and NMR structure of human Bcl- $x_{L}$, an inhibitor of programmed cell death. Nature 381: 335-341

31. Minn AJ, Velez P, Schendel SL, Liang H, Muchmore SW, Fesik SW, Fill M and Thompson CB (1997) Bcl-x $x_{L}$ forms an ion channel in synthetic lipid membranes. Nature 385: 353-357

32. Majumder P, Pandey P, Saxena S, Kharbanda S and Kufe D (2000) Mitochondrial translocation of protein kinase $C \delta$ in phorbol ester-induced cytochrome $c$ release and apoptosis. J. Biol. Chem. 275: 21793-21796

33. Nakagawa T, Zhu H, Morishima N, Li E, Xu J, Yankner BA and Yuan J (2000) Caspase-12 mediates endoplasmic-reticulum-specific apoptosis and cytotoxicity by amyloid-beta. Nature 403: 98-103

34. Kirken R, Lincoln A, Fink P and Prochaska L (1995) High yield purification of a four subunit caa3-type cytochrome oxidase from the thermophilic bacterium Bacillus PS3 using fast protein liquid chromatography. Prot. Exp. Purif. 6: $707-$ 715 